\title{
From Involution to Education: A Glance to Chinese Young Generation
}

\begin{abstract}
Chenxi Li
${ }^{1}$ Department of Social Policy, London School of Economics and Political Science, London, England, United Kingdom. Email: C.Li83@lse.ac.uk

ABSTRACT

The popular buzzword "involution", in Chinese "Nei Juan", usually vividly illustrates the many situations across work and study, where one is doing extra work, but this extra workload is unable to yield a valid output. This essay builds on multiple literature around "involution", investigating the causes and harms of education involution. The essay also combines current policy analysis to point out the problems that still remains in today's society. It finally concludes that the fundamental step to combat the trend of "involution" is through the redistribution of education resources and change of social opinions towards education.
\end{abstract}

Keywords: Education, Education Policies, Involution, Inequality

\section{INTRODUCTION}

The term "involution" started to popularize as a buzzword in China's social media platforms around 2020, as it vividly illustrates the many situations across work and study, where one is doing extra work, but this extra workload is unable to yield a valid output [1]. To apply "involution" in the education sector, there are often times when students are making additional effort not because they are required to, but only due to factors such as unhealthy comparison. This leads to multiple problems, not only regarding students' health but also a lurking threat to the future of the Chinese young generation. As they grow older, this "involuted" mindset would generally evolve into a mob mentality, eventually leading to an unhealthy social behavior.

Under the above situation, this essay seeks to extend the concept of "involution" in the education sector. In light of Huang's definitions, it explores the causes and harms of "education involution" in China, with current policy analysis and potential ways to combat the trend.

\section{THE DEFINITION OF INVOLUTION}

The term "involution" was widely used in fields across agriculture, politics, economics, education and so on. It originally came from the work of an anthropologist, Alexander Goldenweiser, who coined this term to describe cultural reforms such as Gothic
Architecture. As the architecture itself has evolved into a rigid form, it can only continue to develop through internal complexity[2] [3].

The meaning was further diversified and applied in Clifford Geertz's work, proposing the concept of agriculture involution. During field analysis, he was able to find out that certain geo-political restrictions apply to people living in Java, that they keep investing labor forces in the local agricultural industry. This ultimately establishes a relation between overelaboration of labor and a static expansion of output in this small Indonesian island [3].

Zongzhi Huang was one of the earliest scholars that apply "involution" in the Chinese context. Huang used this word to describe the peasant economies in ancient China when a large population faces scarce resources [4]. To make a living, people continue to invest high intensity labor into agricultural products that make relatively lower marginal profits. To illustrate it in graphs, when labor force continues to increase, the profits would grow but at one time (t1) eventually remains still, for which is also the time involution starts. Meanwhile, the marginal profits (includes social recognition, class, status, and such that are not directly profited) would decrease after $t 1$. 


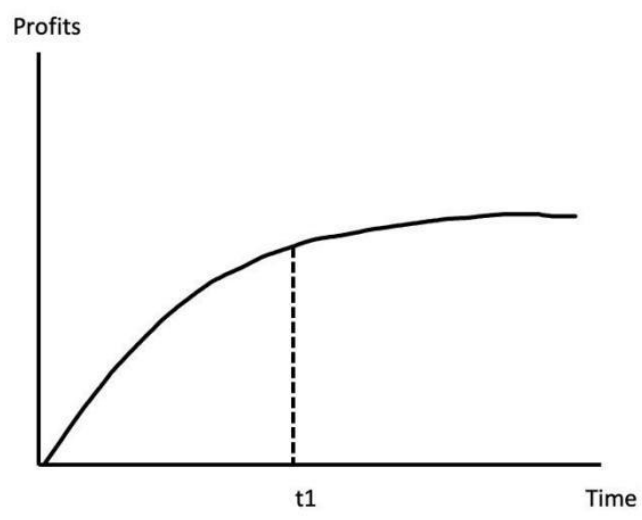

Figure 1. the Relation between Profits and Time

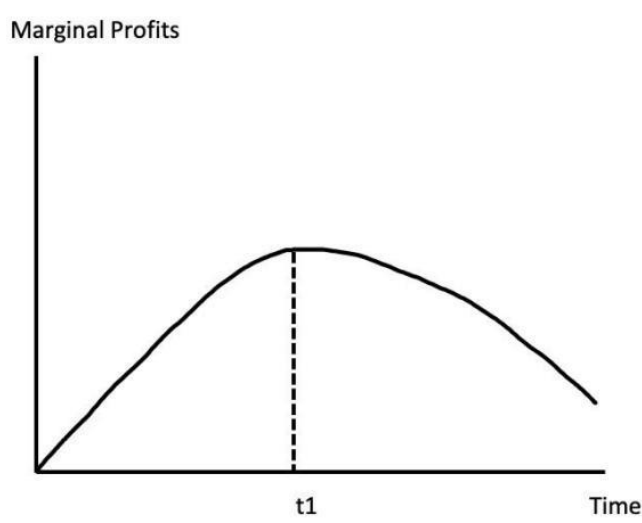

Figure 2. the Relation between Marginal Profits and Time

Based on the above literature, the meaning of "involution" could be simply summarized as follows:

Quantitatively speaking, the overelaboration of inputs is not able to yield an equal output, receiving relatively less marginal gain.

Qualitatively speaking, rather than evolve into a more effective process, the process continues with more internal complexity, such that internal systems become more intricate.

\section{3. "INVOLUTION" IN EDUCATION}

The first reason of "education involution" is the unequal distribution of education resources. Though China has made huge progress in eliminating ruralurban differences these years, the education gap remains. According to the Rural Education Action Program by Stanford, more than $70 \%$ of urban students go to college while less than $5 \%$ of students from rural areas do in China [5]. Meanwhile, with better economic development nation-wide, many families seek to develop in urban areas to have wider access to more resources. This rural-urban migration thus resulted in a burgeoning urban population, making the limited education resource far scarcer. This creates multiple problems. First, as education opportunities are decreasing, the bars to enter certain schools are raised to a higher level. Even entering kindergarten was regarded as a difficult battle for parents, as they must queue for limited places. Some would even sign up for mock interview training for their children just to enter a good school [6], let alone entering middle school or even high school. Therefore, corresponding to the concept of "involution", when highly incensed populations are competing for limited education opportunity, school's selection system becomes more complicated to select better students from the alike pool.

Secondly, the "involuted" education occurs in Chinese society, because people could possibly benefit from being educated. This is deeply believed in Chinese society, that getting a good education would secure one's job, especially by the ever-increasing middle-class group. Moreover, the one-child policy that had been implemented in China for over 30 years also had an impact on family views towards education. Though the only child in a family could benefit from all household resources, they are also pushed under all family member's expectations. Thus, as more people want to get a good education compared to before, the demand in education becomes higher, while the competition becomes more intense.

To be more specific, how the phenomenon of involution develops in the field of education was mainly in the over-spending of time in education. As mentioned above, in order to get into a good school, students have to prove their eligibility in the competition for grades or other qualities among hundreds or even thousands of students. To get ahead in the competition, it has become a common phenomenon for Chinese students (under-18) to have an intense schedule of tutoring classes outside school. Some of these tutoring classes are costly, and some are even exceeding school curriculum. However, students themselves even sacrifice their sleep time just to get a good grade. According to a survey including a sample of 1100 students, only 3\% of Chinese middle school students have an 8-hour sleep every day. As high as $19.5 \%$ of students do not sleep for more than $4-5$ hours [7]. The learning curve theory, illustrating a relationship between time spent and learning productivity, suggests that as one spends more time in study, the curve eventually becomes flat or even decreasing at one time due to diminishing marginal utility [8]. As a result, the cramming of knowledge and over-investing of time not only leads to more stress, but also exert counter effects on student's learning productivity. 


\section{BEHIND INVOLUTION: THE REAL PROBLEMS}

To be more specific, the trend of involution will mainly result in three aspects. Firstly, it will lead to more homogeneity in society. As indicated above, involution is an unhealthy social behavior. Due to human nature, when one is holding an involuntary mindset when doing things, others will ultimately follow this behavior as they are afraid of falling behind [9]. For example, there is an alike tendency for many Chinese graduates to step into high-paid industries such as finance. In order to enter the high bars of companies, a huge number of students will compete by learning similar kinds of concepts, practicing similar kinds of skills. This not only results in greater pressure in the job market, but also a huge amount of alike human forces in society. And meanwhile, there will be a considerable lack of human resource in other fields such as science and arts.

Besides, involution signals an entrenched education inequity. It is a universally acknowledged fact that affluent families are more likely to have a better education with more education products and services at purchase [10]. In China, the difference in regional developments again contributes to the unequal distribution of educational resources. People are further bound by the national Hukou system (household registration), that restricts them to the education in their regions that cannot easily change, and thus affecting the overall educational outcome [11]. In other words, people born in educationally disadvantaged areas cannot even get an entry ticket to this so-called "involution" competition, as there are no resources at disposal. While urban families are busy competing, there is nothing being done to fight against this phenomenon. As a result, it would only end up as the rich being richer while most poor people still remain poorer.

Lastly, being in the loop of involution is a sign of self-flagellation. There was an article once prevalent on Chinese social media platforms, illustrating a parent who has a monthly salary of 30,000 Yuan but still cannot afford their child's summer vacation [12]. This was common for Chinese families to book extracurricular classes for their children during summer. Though lots of these classes are teaching students concepts far beyond the school curriculum, parents are still paying for them to compete. Thus, it was common to see Chinese students' schedule being arrange full even during holidays. However, in a survey done by Chen et al., with a total of 3886 Chinese teenagers participating, their depression rate was as high as $57.0 \%$. This regression analysis has shown that the positively associated variables are mainly senior secondary school enrollment, and concerns about entering a higher grade. Therefore, the immense pressure this has caused for Chinese students is unignorable [13].

\section{CURRENT POLICY ANALYSIS: A CRACKDOWN IN CHINESE PRIVATE TUTORING AGENCIES}

In the past years, though targeted policies have continued to be implemented, there is little change in some of the biggest problems in Chinese education, such as education inequality, liberal arts education, etc. 2020 is a year of change, as the government has so far announced a series of revolutionary education policies, trying to restore a clean and healthy education environment [14].

The biggest move was the government's decision to crack down on outside-school private tutoring agencies. Tutoring for any academic disciplines are strictly controlled and supervised, that is the education content they provide must be following government guidance and cannot take students weekend times as class time.

Overall, this policy is advantageous. As mentioned earlier, private tutoring agencies have become one of the catalysts that stimulates competition in Chinese society. To earn profit, the way they market themselves is based on the anxiety of Chinese parents, and thus exerting more pressure in Chinese societies. Private tutoring is also contributing to education inequality, as low-income families are usually not able to afford them. Restricting private tutoring, at a certain level, alleviates student's pressure, making education more equal and fairer. It also signals the beginning of so-called "Su Zhi Jiao You" in Chinese education, namely developments in student's soft skills.

Nevertheless, the fundamental problem of Chinese education still waits to be addressed. As long as there is demand with a limited resource, scarcity exists. With the intense competitions between Chinese students and families, there will be other ways for students to enhance their academic performance. In the meantime, the government was also announcing its recognition for vocational schools, setting a future goal for half of the middle school graduates to enter vocational schools in the future. This makes the opportunities to enter higher education much less, again stimulating the competition between students.

\section{CONCLUSION}

In conclusion, involution is a word that originally used to describe agriculture and economies. As a wide discussion of "involution" had started around 2020 on Chinese social media, it soon became a hit topic that resonated with thousands of Chinese youngsters. The essay addresses this issue from three perspectives, the 
form of "involution" in education, the reasons for its being, and the potential harms it may cause.

Firstly, the fundamental step to combat the trend of "involution" is through the redistribution of education resources. Unequal education resources not only promote competition but also exerts great anxieties to students and families, as they always have to compete for the limited opportunities. To eliminate education inequality, the government should try to distribute education resources to ensure education equity. Secondly, society's opinions towards education should be changed. It was widely believed by Chinese families that education outcomes are expressed through scores, and that getting into good schools is the only way for their children to secure a good living in the future. These values are the primary source of anxiety, as well as where the concept of "competition" begins. In order to get rid of these social values, schools should hold more extra-curricular activities at schools.

Stepping into 2021, under the fast-changing global situation, the field of education is also embracing rapid new changes. The emergence of Covid-19 has led to the booming of remote learning, and numerous other challenges that wait to be addressed. It should be noted that the topic of "involution" today is not only limited to academic discussion, but a social problem that is recognized by the wide public. However, the discussion should be extended from social media and to apply in real society. Instead of continuing to create anxieties, teachers, scholars as well as parents should step out of the frame, working together to solve the puzzle.

\section{REFERENCES}

[1]Wang, Q., \& Ge, S. (2020, November 5). How one obscure word captures urban China's unhappiness. Sixthtone. Retrieved October 24, 2021, from https://www.sixthtone.com/news/1006391/howone-obscure-word-captures-urban-chinasunhappiness.

[2]Hui, Y. 2009. The unchanging world of peasants: Two perspectives. SOJOURN: Journal Of Social Issues In Southeast Asia 24 (1): 18-31.

[3]Geertz, C. (1963). Agricultural involution. Published by University of California Press.

[4]Huang, P. C. (2000). Hua Bei de Xiao nong Jing Ji yu she hui Bian qian. Zhong hua shu ju.

[5]https://sccei.fsi.stanford.edu/reap/docs/about_reap. Yang, W. (2019, February 5). China's Rural Education Challenge. China Focus. Retrieved October 24 , 2021,https://chinafocus.ucsd.edu/2019/02/04/china s-rural-education-challenge/.
[6] Ng, N. (2013, October 31). Kindergarten wars: Parents battle for places in Hong Kong. CNN. Retrieved October 24, 2021, from https://edition.cnn.com/2013/10/30/world/asia/hon g-kong-kindergarten-competition/index.html.

[7]Pang, S.-X., \& Li, S.-X. (2010). Involution: A Description of Bottleneck in Education. 26(6), 24 29.https://www.airitilibrary.com/Publication/alDeta iledMesh?DocID=16728742-201011201012020020-201012020020-24-29.

[8]Hirschmann, W. B. (2014, August 1). Profit from the learning curve. Harvard Business Review. Retrieved October 24, 2021, from https://hbr.org/1964/01/profit-from-the-learningcurve.

[9]Raafat, R. M., Chater, N., \& Frith, C. (2009). Herding in humans. Trends in Cognitive Sciences, 13(10), $420-428$. https://doi.org/10.1016/j.tics.2009.08.002.

[10]Kaushal, N, Magnuson, K, Waldfogel, J (2011) How is family income related to investments in children's learning. In: Duncan, GJ, Murnane, RJ (eds) Wither Opportunity? Rising Inequality, Schools, and Children's Life Chances. New York: Russell Sage Foundation, pp.187-205.

[11]Xie, Y, Zhou, X (2014) Income inequality in today's China. Proceedings of the National Academy of Sciences 111(19): 6928-6933.

[12]Ponzini, A. Educating the new Chinese middle-class youth: the role of quality education on ideas of class and status. J. Chin. Sociol. 7, 1 (2020). https://doi.org/10.1186/s40711-019-0113-1 .

[13] Chen, X., Qi, H., Liu, R. et al. Depression, anxiety and associated factors among Chinese adolescents during the COVID-19 outbreak: a comparison of two cross-sectional studies. Transl Psychiatry 11,148 (2021). https://doi.org/10.1038/s41398-021-01271-4.

[14]Ministry of Education of the People's Republic of China. (2021, July). Retrieved October 24, 2021, from http://www.moe.gov.cn/jyb_xxgk/moe_1777/moe_ 1778/202107/t20210724_546576.html. 